\title{
3-D Tomographic Images and Deep Ore-Control in Northern Margin of the North China Plate
}

\author{
Xu CHANG, Yike LIU \\ Institute of Geology and Geophysics, Chinese Academy of Sciences
}

\begin{abstract}
3-D velocity images of the crust beneath the northern margin of the North China Plate have been constructed using P-wave travel time residuals of the latest earthquakes, with the data supplied by Chinese seismic networks.

The seismic image results indicate that there is a lateral heterogeneity in the crust beneath the morthern part of the North China block. The velocity images of the upper crust show features closely related to the tectonic features on the surface. It can be seen from these velocity images of the vertical sections, and from the horizontal slice images at depths of $11 \mathrm{~km}$ and $16 \mathrm{~km}$ that there exist East-West and North-East structures. The images indicate that the juncture zone of basin-and-range terrain is between the blue high-velocity block corresponding to the Yanshan mountain range that developed during the Yanshan period in northwest Beijing and the green low-velocity area corresponding to the North China basin in Southeast Beijing. The juncture zone between high-velocity and low-velocity and NE-EW fault zones have significant ore-control effects. From the chart of epicenters in the northern region of North China, we find that the epicenters of earthquakes are almost entirely distributed within the NE strip. Almost all major earthquakes took place in the transition strip between the high and low-velocity zones in the crust. The distribution of epicenters also reflects the strikes of known NE-faults. From the longitudinal image sections, we find that in the area between $114.0^{\circ} \mathrm{E}-118.0^{\circ} \mathrm{E}$, there is a blue high-velocity block standing upright from the Moho to the upper crust, from which can be deduced that some materials such as magma moved upward from the upper mantle during the history of its geological development.
\end{abstract}




\section{Introduction}

The northern margin of the North China Plate is situated at the conjuncture of the Palaeo-Asia Ocean domain and the Pacific Ocean domain and the conjuncture of the Tianshan-Yinshan latitudinal tectonic belt and the Neocathaysian structural system (Cui, 2000). Structures on the surface displays the tectonic-igneous belt along both main EW and NNE directions in the northern margin of North China (Cheng, 1994). Geophysical data, especially data of gravity and magnetic fields, has also shown that within the lithosphere of the northern margin of North China there exists a three-layer tectonic pattern with a variety of structural systems of different depths, that compound the EW and NE trend structures (Sheng, 1987) and that each kind of geophysical field contains certain geological and tectonic information of deep crust. Located in the northern margin of North China, it came through a few orogenesis types and underwent strong tectonic-igneous rock activity in different geological periods. This created strong metallogenic settings and formed various gold, silver and base-metal deposits. Since the big different type structure belts on the surface have the special foundation of their deep structures, it is necessary to study how the two dimensional structure of the surface developed into the three-dimensional structure of the lithosphere. The above characteristics are directly related to the complex tectonic pattern of the northern margin of the North China Plate tectonic zone, which in turn impact on the lithosphere tectonization in China. Therefore, study of the tectonic features of the northern margin of the North China Plate tectonic zone is necessary to understand the evolution, form and distribution of minerals in the lithosphere. In this paper, we use the seismic tomographic method (Liu and Liu, 1998; Chang and Liu, 2000) to reconstruct the 3-D velocity structures of the northern margin of the North China Plate. Based on the seismic velocity images, we deduced the deep ore-control.

\section{Tectonic Setting of the Northern Margin of the North China}

The study area located in the northern margin of the North China Plate, from $34.0^{\circ} \mathrm{N}$ to $44.0^{\circ} \mathrm{N}$ in latitude and $110.0^{\circ} \mathrm{E}$ to $120.0^{\circ} \mathrm{E}$ in longitude, consists of blocks, basins, orogenic belts and fold systems. Fig.1 shows the tectonics of the study area and its circumjacent. In the northern margin of the North China Plate, there are both Zhunger-Xingan 
$\left(\mathrm{I}_{1}\right)$ and Tianshan-Chifeng $\left(\mathrm{II}_{1}\right)$ active belts. The North China Plate $\left(\mathrm{II}_{3}\right)$, consolidated in the late Proterozoic era, is located in the south in the study (Feng, 1989; Cheng, 1994; Wu and Deng, 1994). It consists of an epicontinental zone in the west and a rift zone in the east. The crust movement and the strength of orogenic movement in the northern margin of the North China Plate was strongest during the Yanshan period. This period also involved volcanic explosions, magmatic intrusions, fault movements and heat liquid metallic ore deposits.

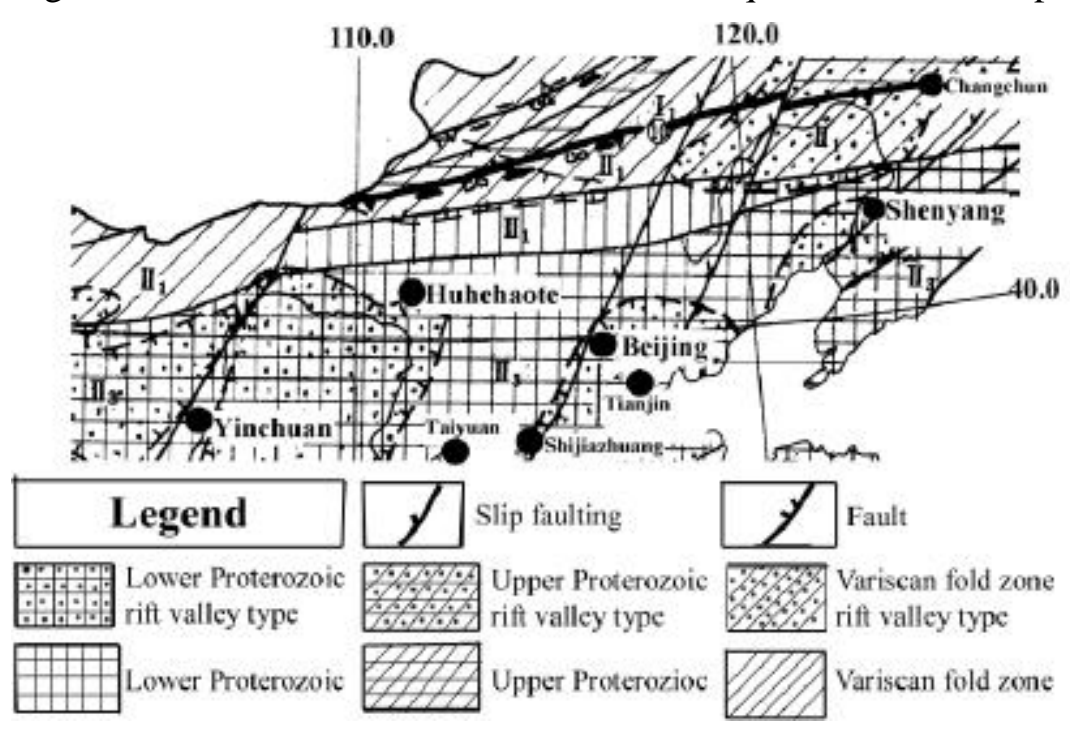

Data courtesy of Huang Jiqing

Fig.1 the tectonics of the study area and its circumjacent.

As this paper focuses on the northern margin of the North China Plate, we have used a more detailed tectonic sketch (Fig .2) of the study area (Cui, 2000). Fig .2 shows that the Erdos is the most stable block $\left(\mathrm{I}_{\mathrm{C}}^{1}\right)$ located in the northwest of the North China Plate. Shanxi block $\left(\mathrm{I}_{\mathrm{C}}^{2}\right)$ is a craton and formed basin-ridge structure which resulted from rift-uplift movements. The Inner-Mongolia uplift belt $\left(\mathrm{I}_{\mathrm{C}}^{3}\right)$ along the EW direction, developed an extended type rift basin in the form of the Huhehaote-Baotou rift basin. Yanshan mountain is an intracontinental orogen $\left(\mathrm{I}_{\mathrm{C}}^{4}-\mathrm{I}_{\mathrm{C}}^{5}\right)$ developed from the foundations of craton in the Mesozoic-Cenzoic era. Wenduermiao-Wengniuteqi Caledonian folding $\left(\mathrm{II}_{\mathrm{C}}^{5}\right)$ is located in the northern and middle areas of the lithosphere rift zone of the northern margin of the North China plate and in the south in the Wenduermiao-Xilamulun river deep rift. The 
SuniteyouqiLinxi late-Variscan folding belt $\left(\mathrm{II}_{\mathrm{C}}^{4}\right)$ is located in the area north of Wenduermiao-Xilamuluo river deep rift belt and south of Ailigemiao-Xilinhaote block $\left(\mathrm{II}_{\mathrm{C}}^{3}\right)$.

The Sunitezuoqi-Xiwuzhumuqinqi Late-Variscan folding belt $\left(\mathrm{II}_{\mathrm{C}}^{2}\right)$ is located in the area north of the Ailigemiao-Xilinhaote block, and south of the Erlian-Hegenshan deep rift. The Dongwuzhumuqinqi Early-Variscan folding belt $\left(\mathrm{II}_{\mathrm{C}}^{1}\right)$ is located north of the Erlian-Hegenshan deep rift (Cui and li, 1990; Shao, 1991; wang, 1992; Niu, 1993).

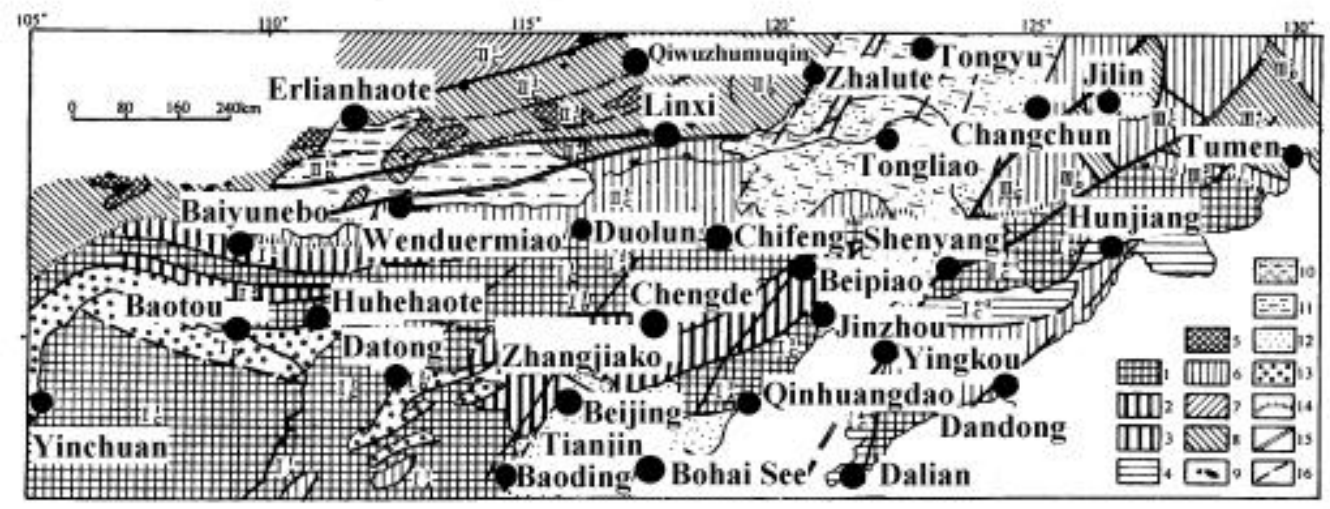

\begin{tabular}{|l|l|l|}
\hline \multicolumn{3}{|c|}{ Legend } \\
\hline 1. Ar-Pt1 landmass & 7. Lower variscian fold zone & 13. Fen-Wei-Hu-Bao rift basin \\
\hline 2. Pt1 active belt & 8. Upper Variscian fold zone & 14. The northern boundary of North China landmass \\
\hline 3. Pt2 indentation & 9. Ophiolite & 15. Deep fault zone \\
\hline 4. Pt3-PZ downwarping & 10. Songliao rift basin & 16. Region fault zone \\
\hline 5. Middle land block & 11. Erlian rift basin & \\
\hline 6. Caledonian fold zone & 12. Xia Liaohe-North China rift basin & \\
\hline
\end{tabular}

Data courtesy of Cui Shengqin

Fig.2 Sketch of North Margin of the North China

\section{Study Data}

The data was collected from 93 seismic stations in the area. A total of 3,278 earthquakes that occurred in the area from 1993 to 1999 were selected for the study, with the magnitudes of such earthquakes being greater than $1.0 M_{L}$ on the Richter scale.

To ensure the accuracy of the initial seismic source locations, data of the earthquakes within the study area was taken from the local networks of China. A total of $26,074 \mathrm{P}$ - wave arrival times were used, with the error in the arrival time picks being generally less than 0.2 seconds. The altitude of stations is corrected automatically. The distribution of the seismic stations and regional earthquake epicenters used for this study are shown in Fig. 3 and Fig. 4, 
respectively.

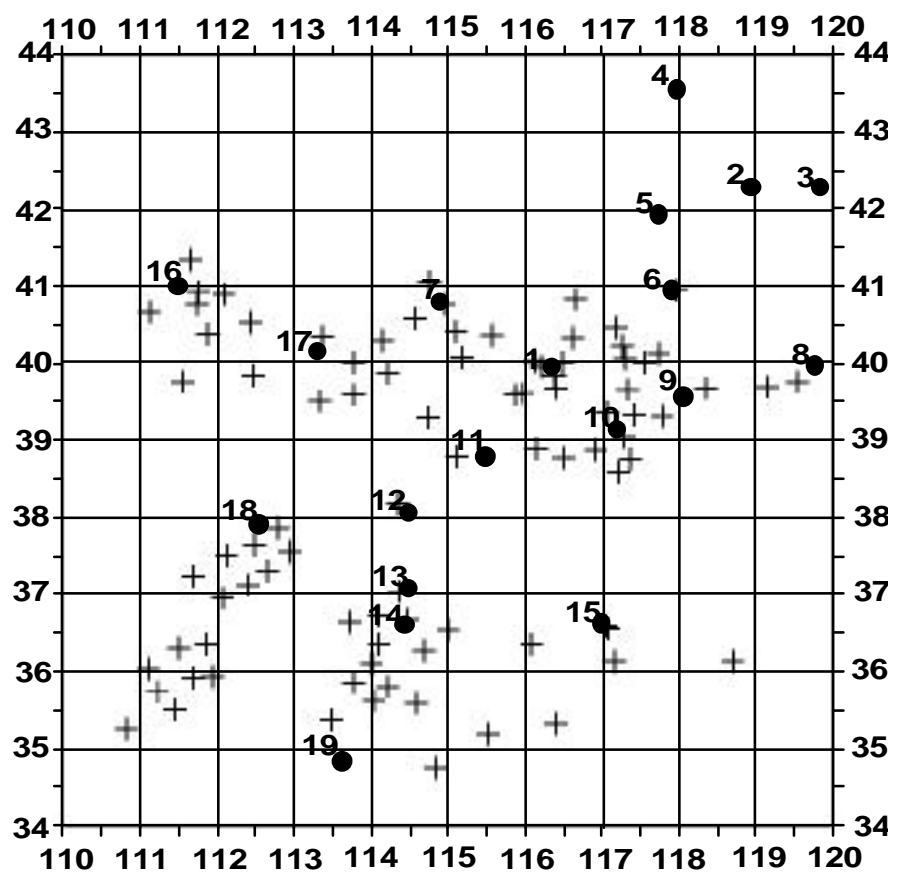

Fig. 3 Distribution of stations. The "+" mark shows the position of a station. The solid circle shows the position of the major city in the study area, and Arabia numbers near by the solid circle are the sequence numbers corresponding to the city's name shown in table 1 .

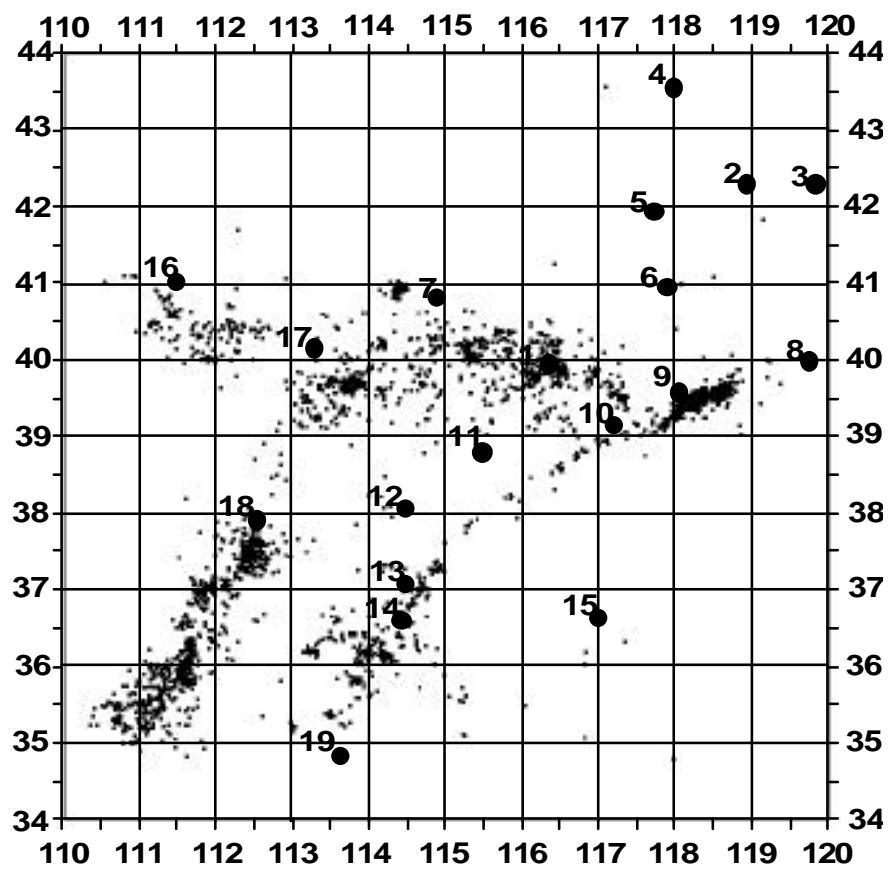

Fig. 4 Distribution of earthquake epicenters. The "." mark shows the position of an earthquake epicenter. The solid circle shows the position of the major city in the study area, and Arabia numbers near by the solid circle are the sequence numbers corresponding to the city's name shown in table 1 . 
Table .1 The city's name and the sequence number

\begin{tabular}{cc|cc|cc|cc}
\hline No. & City name & No. & City name & No. & City name & No. & City name \\
\hline 1 & Beijing & 6 & chengde & 11 & Baoding & 16 & Huhehaote \\
\hline 2 & Chifeng & 7 & Zhangjiakou & 12 & Shijiazhuang & 17 & Datong \\
\hline 3 & Aohanqi & 8 & Qinhuangdao & 13 & Xingtai & 18 & Taiyuan \\
\hline 4 & Linxi & 9 & Tangshan & 14 & Handan & 19 & Zhengzhou \\
\hline 5 & Weichang & 10 & Tianjin & 15 & Jinan & 20 & \\
\hline
\end{tabular}

Table 1 shows the major cities that correspond to the Arabic number shown in Fig.3.

To reconstruct the detailed seismic velocity images, the grid spacing has been made as small as possible. In the horizontal direction the grid is $0.5^{\circ} \times 0.5^{\circ}$, and in the vertical direction the grid spacing is $1 \mathrm{~km}$. In this paper we use the values $I=21, J=21, K=41$, resulting in a total of 16,000 nodes.

Table 2 indicates that earthquake sources selected from the North China earthquake stations network from 1993 to 1999 . Table 3 indicates the seismic waves travel time data selected from North China earthquake station network from 1993 to 1999.

Table 2 The number of earthquakes from 1993-1999

\begin{tabular}{cccccc}
\hline YearlQuarter & First & Second & Third & Fourth & Total \\
\hline 1993 & 90 & 80 & 163 & 110 & 443 \\
\hline 1994 & 147 & 124 & 41 & 97 & 409 \\
\hline 1995 & 101 & 95 & 98 & 171 & 465 \\
\hline 1996 & 115 & 138 & 75 & 205 & 533 \\
\hline 1997 & 154 & 166 & 133 & 154 & 607 \\
\hline 1998 & 118 & 51 & 111 & 85 & 365 \\
\hline 1999 & 80 & 115 & 93 & 168 & 456 \\
\hline Total & 805 & 769 & 714 & 990 & 3278 \\
\hline
\end{tabular}

Table 3 Seismic event data (the number of seismic wave rays)

\begin{tabular}{cccccc}
\hline YearlQuarter & First & Second & Third & Fourth & Total \\
\hline 1993 & 710 & 654 & 1209 & 827 & 3400 \\
\hline 1994 & 1002 & 927 & 282 & 758 & 2969 \\
\hline 1995 & 780 & 662 & 598 & 1548 & 3588 \\
\hline 1996 & 888 & 1130 & 506 & 1832 & 4356 \\
\hline 1997 & 1091 & 1250 & 867 & 1378 & 4586 \\
\hline 1998 & 976 & 496 & 1042 & 738 & 3252 \\
\hline 1999 & 678 & 881 & 726 & 1638 & 3923 \\
\hline Total & 6125 & 6000 & 5230 & 8719 & 26074 \\
\hline
\end{tabular}




\section{Inversion Method of Seismic Tomography}

\subsection{Parameterization of the model}

To reconstruct velocity images, we assume that the Earth is an isotropic, elastic layered medium. The high-frequency asymptotic approximation for seismic waves from a point source is also assumed. The travel time from source $i$ to receiver $j$ can be expressed as

$$
T_{i, j}=\int_{L_{i, j}} \frac{d s}{v}
$$

where $v$ is the seismic wave velocity, $d s$ is a segment of seismic ray path and $L_{i, j}$ is the ray path from $i$ to $j$. In a spherical coordinate system, the differential equations of the path are as follows (Cerveny et al., 1977; Liu et al., 1990).

\subsection{Formulation of the Problem}

From equation (1) we know that the travel time is given by an integration along the ray path. On the other hand, the path itself depends upon the velocities in the medium. Therefore the tomographic problem will be highly nonlinear if equation (1) is used for velocity inversion. We can linearize the problem in the following way:

$$
\delta T_{i, j}=T_{i, j}^{o b s}-T_{i, j}^{c a l}=\int_{L_{i, j}} \delta \frac{1}{v} d s+\varepsilon_{i, j}
$$

Where $T_{i, j}^{o b s}$ is the observed travel time, $T_{i, j}^{c a l}$ is the travel time calculated by ray tracing in a reference velocity structure $v_{0}$ and corrected for station altitudes, and $\boldsymbol{\varepsilon}_{i, j}$ is an error term including the clock and reading errors. It is assumed that the positions of sources are accurate. The first term in equation (2) is the change in the travel time caused by a velocity perturbation $\delta v$ relative to $v_{0}$. According to Fermat's principle, the effect of the change in the ray path caused by this perturbation on the travel time is of the second order. Therefore the ray path $L_{i, j}$ can be determined by a ray-tracing equation according to the 
reference velocity $v_{0}$. Consequently we can write

$$
\int_{l_{i, j}} \delta\left(\frac{1}{v}\right) d s=\sum_{l=1}^{N L} \delta t, \quad \delta t_{l}=\int_{s_{l-1}}^{s_{l}} \delta\left(\frac{1}{v}\right) d s
$$

where $l$ denotes the $l$ th segment of the path $L_{i, j}$. It starts from $S_{l-1}$ and ends at $S_{l}$, where the corresponding velocities are $v\left(s_{l-1}\right)$ and $v\left(s_{l}\right)$, respectively. $N L$ is determined by ray tracing. As long as the path does not cross any discontinuity surface, the sign of the integrand $\delta\left(\frac{1}{v}\right)$ remains the same within the integral limits, then by mean-value theorem

$$
\delta t_{i}=\frac{\Delta s_{l}}{2}\left[\delta\left(\frac{1}{v_{l-1}}\right)+\delta\left(\frac{1}{v_{l}}\right)\right], \quad \Delta s_{l}=s_{l}-s_{l-1}
$$

We have improved the method by using spherical coordinates system for $v$ (Liu et al., 1993), we have

$$
\delta t_{l}=\frac{1}{2}\left[\frac{\Delta s_{l}}{v\left(s_{l-1}\right)} \sum_{a_{1} \in H} f_{a_{1}}\left(-\frac{\delta v_{a_{1}}}{v_{a_{1}}}\right)+\frac{\Delta s_{l}}{v\left(s_{l}\right)} \sum_{a_{2} \in H} f_{a_{2}}\left(-\frac{\delta v_{a_{2}}}{v_{a_{2}}}\right)\right]
$$

where

$$
f_{a_{1}}=F_{a_{1}} \frac{v_{a_{1}}}{v\left(s_{l-1}\right)}, \quad f_{a_{2}}=F_{a_{2}} \frac{v_{a_{2}}}{v\left(s_{l}\right)}
$$

Defining the relative slowness perturbation $x_{a}$,

$$
x_{a}=-\frac{\delta v_{a}}{v_{a}}=\frac{\delta u_{a}}{u_{a}}
$$

where $u_{a}=1 / v_{a}$ is the wave slowness. Finally the first term in equation (2) becomes

$$
\delta T_{i, j}=\frac{1}{2} \sum_{l=1}^{N L}\left[\frac{\Delta s_{l}}{v\left(s_{l-1}\right)} \sum_{a_{1} \in H} f_{a_{1}} x_{a_{1}}+\frac{\Delta s_{l}}{v\left(s_{l}\right)} \sum_{a_{2} \in H} f_{a_{2}} x_{a_{2}}\right]
$$

The ray paths in equation (8) will be determined by two-point ray tracing (Cerveny et al., 1977). Using spherical coordinates system (Liu et al., 1993), the matrix expression of equation (8) for the ith earthquake is

$$
A X^{i}=\delta t^{i}
$$

For a total of $m_{e}$ earthquakes we have 


$$
A X=\delta t
$$

where $A$ is an $m \times n$ matrix whose elements are given by (6). Supposing that there are $n_{s}$ stations in operation in the study area, then $m=m_{e} \times n_{s}, n=I \times J \times K$. Because of uneven source and receiver distributions and linearization of inversion problems, there exists an ill-posed problem when solving the equation. There may be inconsistencies in the equations or more parameters than equations. Equation (8) may have no solution, or there may be no unique solution. If the condition number of matrix $A$ is too big, the process to find equation (8) is not unstable, which will cause an algorithm instability. Therefore, choosing a suitable algorithm for an ill-posed problem is an important prerequisite for deriving a true solution.
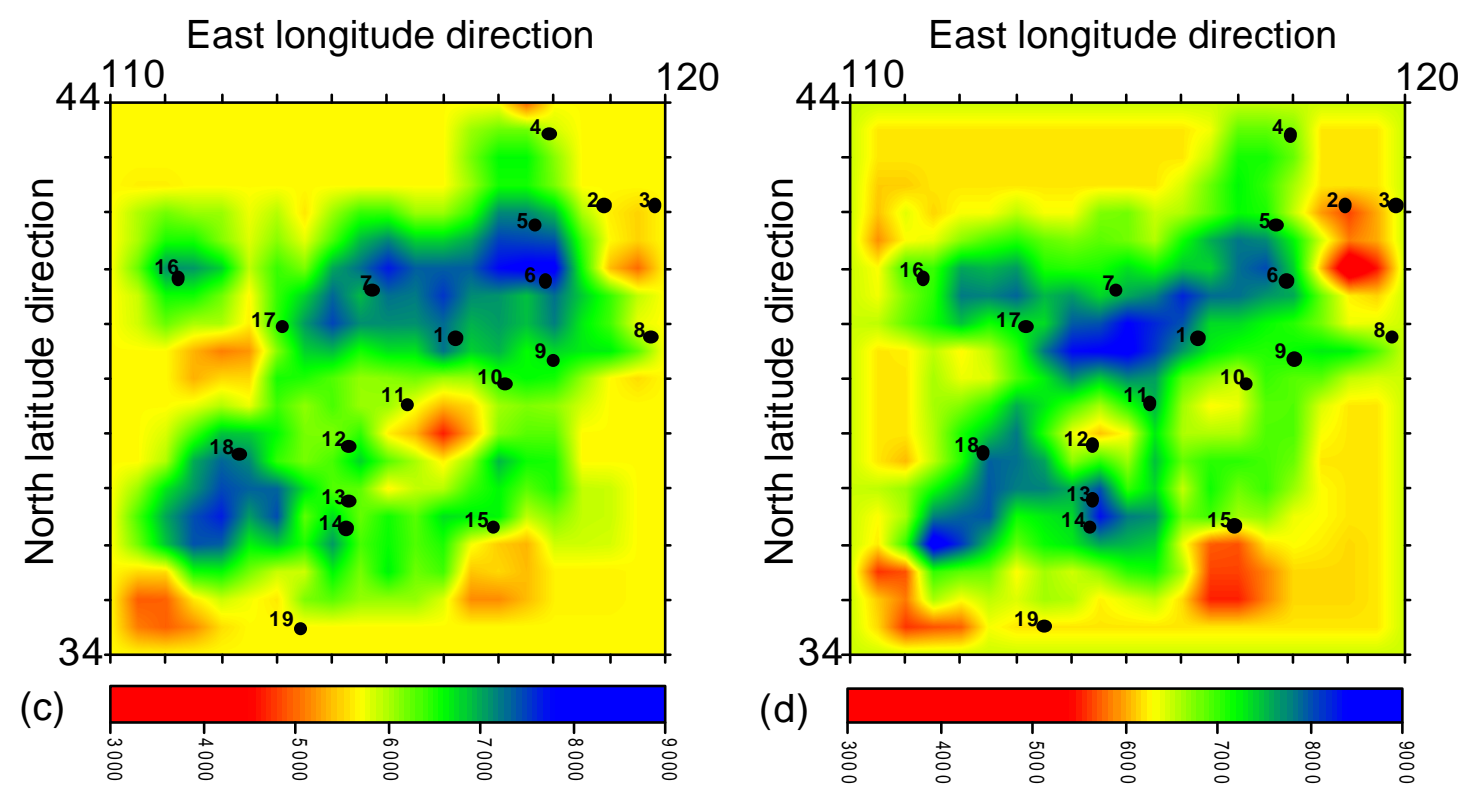

Fig . 5 The slices of velocity image at $11 \mathrm{~km}$ and $16 \mathrm{~km}$ depths. The solid circle shows the position of the major city in the study area, and Arabia numbers near by the solid circle are the sequence numbers corresponding to the city's name shown in table 1.

\section{3-D Seismic Velocity Images of North Margin of North China Plate}

We reconstructed the 3-D seismic velocity images by using the earthquake data of the northern margin of the North China Plate. Aimed at the interesting areas, we developed two slices at depths of $11 \mathrm{~km}$ and $16 \mathrm{~km}$ and two cross sections from the 3-D seismic velocity data 
volume between $110^{\circ}$ to $120^{\circ}$ and $34^{\circ}$ to $44^{\circ}$. The average depth of Moho is about 32km. In Fig.5 and Fig.6 red represents low velocity zones, while blue indic ates high velocity zones, as shown by the color bars.

Fig.5 (a) and (b) show the velocity slices at depths of $11 \mathrm{~km}$ and $16 \mathrm{~km}$, respectively. The seismic image results indicate that there is a lateral heterogeneity in the crust beneath the northern margin of the North China Plate. It can be seen from these velocity slices that there exist EW-NE structures at the given depths which correspond to the structures on the surface and that the distribution of epicenters (Fig.4) also reflects the strikes of known NE-faults. Comparing the locations of epicenter distribution in Fig.4 with the images in Fig.5, we find from Fig.5 (a) and (b) that most of the earthquakes are located on the boundaries between the low-velocity and high-velocity zones. These faults play role in controlling the distribution of mineral resources.

Fig.5 (a) shows the image of velocity distribution at a depth of $11 \mathrm{~km}$. The image displays the lateral heterogeneity of seismic velocity in the upper crust. From Huhehaote (No.16) through Zhangjiakou (No.7) to Chengde (No.6), the structure of the EW with blue high-velocity perturbations, corresponds to the development of the Inner-Mongolia uplift belt and Wenduermiao-Wenniuteqi Caledonian folding system. A blue high-velocity strip with $7.5 \mathrm{~km} / \mathrm{s}$ that appears in the NE corresponds to the structure on the surface, though the velocity strip displays discontinuity between the area from Shijiazhuang (No.12) and Datong (No.17). The velocity under the Chengde (No.6) is apparently high, with a value of more than $8.0 \mathrm{~km} / \mathrm{s}$. The high-velocity region corresponds to the Fenwei fault system and Xialiaohe-North China fault system (Ma, 1989). A green low-velocity area exist within a very wide region of the upper-crust, and the lowest velocity value reaches near $5.0 \mathrm{~km} / \mathrm{s}$ in the southwest of Tianjin (No.10). In a strip area between $31.8^{\circ} \mathrm{N}-33.4^{\circ} \mathrm{N}$ and $116.0^{\circ} \mathrm{E}-118.0^{\circ} \mathrm{E}$, the low-velocity anomaly with a value of $5.4 \mathrm{~km} / \mathrm{s}$ appears in the upper crust. Compared with the adjacent region, Linxi (No.4) demonstrates slightly high velocity at $6.0 \mathrm{~km} / \mathrm{s}$.

Fig.5 (b) is similar to the velocity image at a depth of $11 \mathrm{~km}$, reflecting the lateral heterogeneity of the velocity in the mid-crust. In terms of the EW and NE direction structures, compared with the image of $11 \mathrm{~km}$, an anomaly strip from Huhehaote (No.16) through Datong 
(No.17) to Baoding (No.11) shows the high-velocity in the image of $16 \mathrm{~km}$. The size of green and red low-velocity areas decreases and blue high-velocity area increases. The high-velocity $\mathrm{NE}$ and EW anomaly strips display more clearly than the same region in the image of $11 \mathrm{~km}$. The velocity increases gradually in the Tianjin (No.10) area, but decreases in the Jinan (No.15) and Chifeng (No.2) area.

From Fig.5 (a) and (b), we find that the juncture zone of basin-and-range terrain between blue high-velocity block corresponds to the Yanshan mountain range that developed during the Yanshan period in northwest Beijing (No.1) and the green low-velocity area in southeast Beijing corresponds to the basin of North China. The juncture zone between high-velocity and low-velocity and NE-EW fault zones have significant ore-control effects. Many mineralization belts are distributed in these regions. 

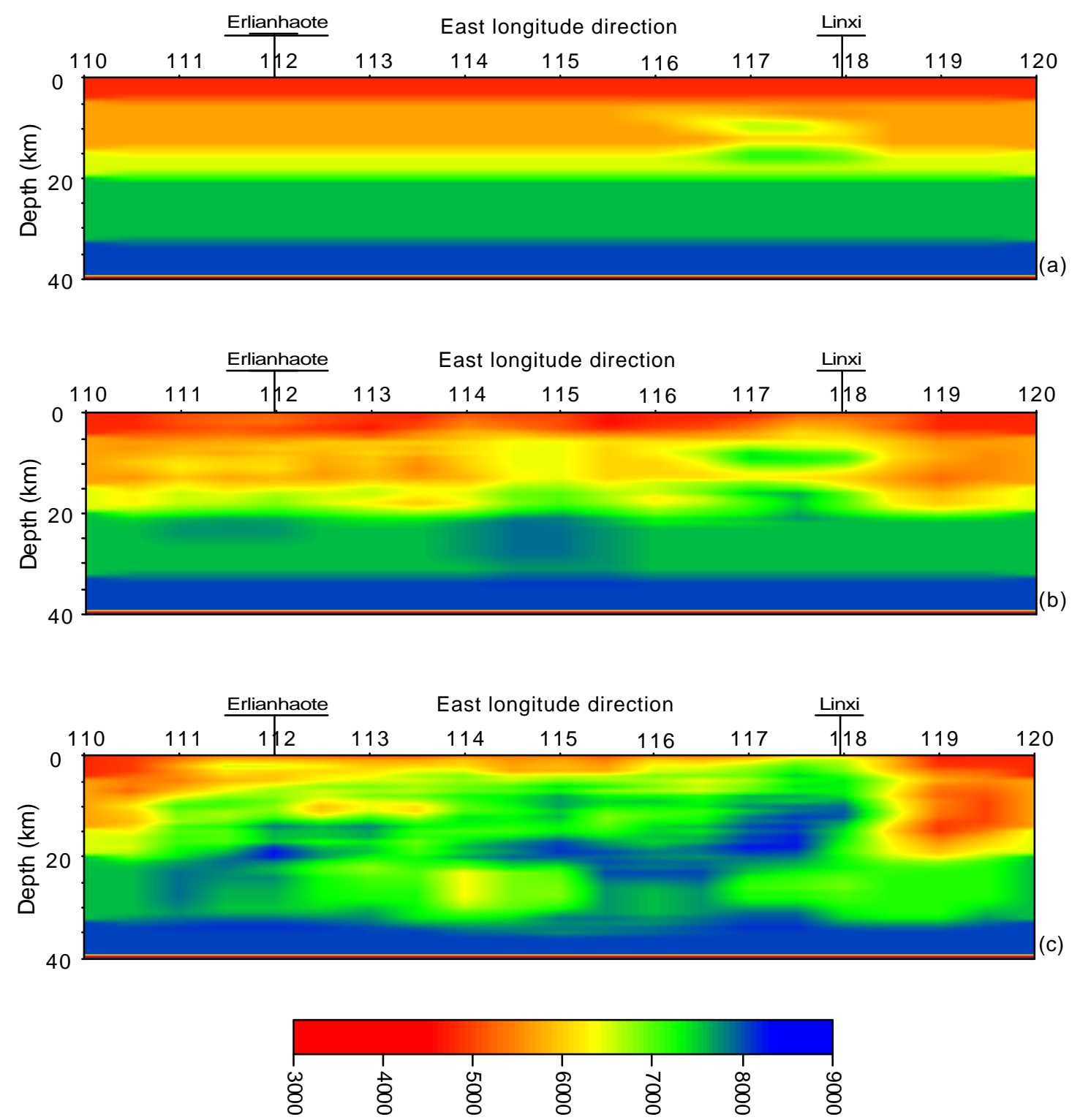

Fig.6 (a) North latitude $43^{0}$ section; (b) North latitude $42^{0}$ section; (c) North latitude $41^{0}$ section.

Fig.6 (a), a section of the velocity image in north latitude $43^{\circ}$, shows that there are stable velocity layers in the section except in the region close to Linxi area. It also shows that there are two high velocity blocks from $9 \mathrm{~km}$ to $11 \mathrm{~km}$ depth and from $13 \mathrm{~km}$ to $17 \mathrm{~km}$ with $7.0 \mathrm{~km} / \mathrm{s}$ between $117^{\circ} \mathrm{E}-118^{\circ} \mathrm{E}$. These blocks are close to the fault belt of Xilamulunhe and possess abundant copper and gold ore deposits.

Fig.6 (b) shows a section of the velocity image in north latitude $42^{\circ}$. The two green high-velocity blocks near Linxi (No.4) at the depths of upper and mid crusts increase compared with the same area in the section of north latitude $42^{\circ}$. A high-velocity anomaly 
appears from Mohe to the mid-crust $\left(114.0^{\circ} E-116.0^{\circ} E\right.$ ). This profile is located at the transitional area between the Inner-Mongolia uplift and the Wengniuteqi Calidonian fold zone. In the Inner-Mongolia uplift, affected by the Xing-Mongolia fold system, there are tectonics, magma and metallogenic ores created in Paleozoic era.

Fig.6 (c) shows a section of the velocity image in north latitude $41^{\circ}$. Unlike the velocity images in the north latitudes $43^{\circ}$ and $42^{\circ}$, there is a significant lateral heterogeneity in the crust beneath the northern part of the North China block. There are low-velocity areas from Moho to the mid-crust in the area between the $112.0^{\circ} E-115.0^{\circ} \mathrm{E}$ and $116.8^{\circ} E-119.8^{\circ} E$, respectively, With the lowest velocity value being about $6.2 \mathrm{~km} / \mathrm{s}$ in the lower-crust area. In the area between $114.0^{\circ} \mathrm{E}-118.0^{\circ} \mathrm{E}$, a blue high-velocity block extending vertically from the Moho to the upper crust, indicates that some materials such as magma moved upward from the upper mantle in the course of geological history. Like the images of the depths of $11 \mathrm{~km}$ and $16 \mathrm{~km}$, the blue high-velocity block $\left(114.0^{\circ} E-118.0^{\circ} \mathrm{E}\right)$ corresponds to the Yanshan mountain range and green low-velocity blocks correspond to the North China Basin and the Bohai Basin. The juncture zone between high-velocity and low-velocity and NE-EW fault zones have significant ore-control effects.

\section{Conclusion}

Based on the latest earthquake data, this paper reconstructed the 3-D velocity images of North margin of North China by using seismic tomography and thereby ensuring the reliability of seismic images. The velocity images display the lateral heterogeneity of seismic velocity above the Moho. There are the NE-EW structures persisting down to $11 \mathrm{~km}$ and $16 \mathrm{~km}$ in the area, which correspond to the tectonic features on the surface. In the Yanshan mountain range, high seismic velocity appears. Low velocity appears in the North China plain and basins. The juncture zone between high-velocity and low-velocity and NE-EW fault zones have significant ore-control effects. Many mineralization belts are distributed in these regions. The epicenters of earthquakes are almost entirely distributed in the NE trips, which are related to the strikes of known NE-faults.

Acknowledgements: We would like to thank Professor Hidehiko Shimazaki for his advice. 
This study was supported by Chinese Academy of Sciences (Project No. KZCX2-112, KZ591-B1-404).

\section{References}

Cerveny, V., Molotkov, I. A. and Psencik, I. (1977) Ray Method in Seismology, Iniverzita Karlova, Praha.

Chang, X. and Liu, Y. (2000) determination of 3-D velocity anomalies of the Nanbei tectonic zone of China based on local earthquake. ACTA GEOLOGICA SINICA, 74, 102-115.

Cheng, Y. (1994) Generality of regional geology of China. Geological press.

Cui, S. (2000) Sequences of tectonic movement and regional tectonic framework of north margin of the North china Plate. Geological press.

Cui, S. And Li, J. (1990) Himalayan tectonic evolution in the East Asian Peri-Pacific region, ACTA GEOLOGICA SINICA, 64, 305-317.

Feng, R. (1989) The crustal structure and earthquake activity in North China. ACTA GEOLOGICA SINICA, 63, 150-163.

Liu, F. and Jin, A. (1993) Seimic tomography of China, In: Seismic Tomography Theory and Pracetice, 299-318, CHAPMAN \& HALL, London, Glasgow, New York, Tokyo, Melbourne, Madras.

Liu, F., Wu H. and Liu, J. (1990) 3D velocity images beneath the Chinese continent and adjacent regions, Geophysical Journal International, 101: 379-394.

Liu, Y. and Liu, F. (1998) Characteristics of geological field in east China and adjacent regions. Geoscience journal, 3, 108-116.

Ma Xingyuan (1989) Lithospheric dynamics atlas of China, China Cartographic Publishing House.

Niu, S. (1993) The tectonic and evolution in Inner-Mongolia during the Paleozoic, Geology Press.

Shao, J. (1991) Th tectonic and evolution of north margin in Sina-Korea platform, Peking University Press.

Sheng, N. (1987) The features of magnetic and gravity fields of epicontinental China and adjacent sea regions World geology. 
Wang, D. (1992) Continental geological structure in Sina-Korea platform. Earthquake press.

Wu, Z. and Deng, S. (1994) The rock structure of crust and upper mantle in North China. Journal of Rock and Mineralogy, 13, 98-105. 